\title{
La venganza
}

RAÚL ANTELO Universidade Federal de Santa Catarina, Brasil / antelo@iaccess.com.br

\section{Resumen}

La literatura (sobre todo la latinoamericana, en Argentina pero también en todas partes) solicita su lectura, exige ser leída. A la vez, es siempre ilegible y su lector es obviamente inexistente, con la salvedad de que esa inexistencia esté sin embargo referida a antecedentes y consecuentes. $\mathrm{Al}$ leer siempre rescatamos presencias obliteradas y presentes esfumados por la simple razón de que, convertida en potencia nihilista, la literatura vaga por el libro de arena pero también gira, anacrónicamente, alrededor de su propio desgarro, en busca de una reserva de imaginación, una contra-historia, a partir de la cual desactivar la inercia. Este texto teórico asume, por lo tanto, que paralelamente a la historia como práctica y discurso a pelo de la soberanía, le sobreviene una contra-historia que señala la servidumbre oscura e involuntaria, la profecía pero también la promesa, cuyos procesos se distinguen en tramados concomitantes de heterologías, heterotopías, heteronomías y heterocronías variadas, cuando no contradictorias.

Palabras clave: lectura / literatura latinoamericana / venganza / teoría literaria

\section{The revenge}

\section{Abstract}

Literature (especially the Latin American one in Argentina, but also everywhere) requests and demands to be read. At the same time, it is always unreadable, and its reader is obviously non-existent, on condition that this non-existence is nevertheless referred to background and consequences. When we read, we always rescue obliterated and present presences that have faded for the simple reason that, turned into a nihilistic power, literature wanders the sand book, but also revolves, anachronistically, around its own tear, in search of a reserve of imagination, a counter-history, from which to deactivate inertia. Therefore, this theoretical text deduces a reading in and of the revenge, since the history as practice and discourse contrary to the sovereignty is followed in parallel by a counter-history that indicates the dark and involuntary servitude, the prophecy, but also the promise, whose processes are distinguished in concomitant patterns of varied, if not contradictory, heterologies, heterotopias, heteronomies, and heterochronies. Latin America in revenge, read in the coextensive way and in the frequently catastrophic effects of the temporal folds: a (new) paradigm that arranges the historical series according to the metaphysics of an absolute and infinite memory.

Key words: reading / Latin American literature / revenge / literary theory

Recibido: 4/6/2018. Aceptado: 9/7/2018

Para citar este artículo: Antelo, Raúl (2018). La venganza. El taco en la brea, 8 (junio-noviembre), 59-65. Santa Fe, Argentina: UNL. DOI: 10.14409/tb.v1i8.7756 
It is therefore quite significant, a structural element in the realm of human affairs, that men are unable to forgive what they cannot punish and that they are unable to punish what has turned out to be unforgivable. Hannah Arendt, The Human Condition

Sabemos que la literatura (sobre todo la latinoamericana, en Argentina pero también en todas partes) exige ser leída, aunque nadie la lea, es decir que, en la medida en que solicita su lectura, una literatura es siempre ilegible y su lector es obviamente inexistente, con la salvedad de que esa inexistencia esté sin embargo referida a antecedentes y consecuentes (Antelo 2016, 2017). Siempre rescatamos, al leer, presencias obliteradas y presentes esfumados por la simple razón de que, convertida en potencia nihilista, la literatura vaga por el libro de arena pero también gira, anacrónicamente, alrededor de su propio desgarro, en busca de una reserva de imaginación, una contra-historia, a partir de la cual desactivar la inercia. Es decir, paralelamente a la historia como práctica y discurso a pelo de la soberanía, hay una contra-historia que señala la servidumbre oscura e involuntaria, la profecía pero también la promesa, cuyos procesos se distinguen en tramados concomitantes de heterologías, heterotopías, heteronomías y heterocronías variadas, cuando no contradictorias.

Al contemplar la historia sub specie aeternitatis, más que de estados de un tiempo fluido, la tarea de la lectura, según Fabián Ludueña, consistiría en pensar

las reglas que gobiernan regímenes de simultaneidad temporal donde la «supervivencia» o «vida póstuma» de las imágenes y sus demonios pueden ser concebidas como intersecciones de vectores temporales coexistentes. El paradigma de los retornos aún obedece a una temporalidad lineal, aunque no progresiva (que admite idas y vueltas en direcciones opuestas) mientras que el desafío consiste en superar esta concepción de la temporalidad a favor de una visión de tiempos superpuestos o coextensivos; una especie de topología de los plegamientos temporales. (38-39)

Estamos, en verdad, asistiendo a una cosmología que nos reclamaría así un punto de fuga desde el cual sea posible ver, como en un Atlas absoluto, todos los puntos de la pre-historia, la historia y la pos-historia de los textos, o en otras palabras, un punto desde el que no veamos nunca la totalidad del tiempo en su devenir, sino, al contrario, una lógica que ordene las series históricas según reglas que obedecen a una metafísica del infinito, la memoria del cosmos. Memoria de globalización.

La venganza, nos dice Benjamin, es siempre originaria; quizás no siempre regia o divina, pero sí nueva. Se manifiesta como si fuera el primer día de la creación y de una manera muy diferente a los viejos clichés con que el pecado se imponía al filisteo. Reconstruyamos, pues, caleidoscópicamente, esa memoria absoluta con la moral del juguete. Así las cosas, veamos que ya Borges argumentaba, en plena hegemonía del radicalismo, que

parece natural que las sociedades padezcan su quantum de rufianes y de ladrones: en lo atañedero a los unos, Cervantes declaró que su oficio era de grande importancia en la república, y en cuanto al robo, el padre del Gran Tacaño dijo que era arte liberal, no mecánica. Lo que sí parece asombroso es que el hombre corriente y morigerado se haga el canalla y sea un hipócrita al revés y remede la gramática de los calabozos y los boliches. Sin embargo, el hecho es indesmentible. En Buenos Aires escribimos medianamente, pero es notorio que entre las plumas y las lenguas hay escaso comercio. En la intimidad propendemos, no 
al español universal, no a la honesta habla criolla de los mayores, sino a una infame jerigonza donde las repulsiones de muchos dialectos conviven y las palabras se insolentan como empujones y son tramposas como naipe raspado. (121)

Pocos años más tarde, tras la gran crisis del capitalismo, el diagnóstico de Martínez Estrada es aún más sombrío. Surge a su juicio el guarango, que necesita un ambiente mayor que el compadre, un público más nutrido, para que su agresión, bajo el aspecto de la broma, siniestra y sociable, resulte triunfal. Es decir que para Martínez Estrada sólo se es guarango cuando hay connivencia entre quienes practican y quienes asisten a la violencia, ya que la grosería en particular, sólo cuando se la proyecta al espacio público, logra esa nueva categoría, la guarangada. Discípulo de Simmel, Estrada cree que el guarango, de la misma matriz (aunque ya gastada) del compadre, falta a las convenciones urbanas, pero no a las sociales, y por eso es incivil y tosco, sin el pulido y desgaste que la sociedad nos impone.

El guarango trae a la memoria del hombre que vive en el centro de un sistema de cortesía, de convenciones morales, de respeto, un hálito paleolítico, un resabio amargo de animal de monte (...). Es un ignorante que interpreta mal la realidad, como el casi analfabeto un texto que puede deletrear pero que no entiende. Y le opone su yo, no frente a frente como el compadre, sino al sesgo, como metiéndose en la tertulia sin permiso. (...) La guarangada es una venganza que se encubre en las apariencias de la irresponsabilidad moral: atropello de pobre que atribuye su déficit moral, pecuniario e intelectual, al bienestar ajeno. El guarango toma precauciones para que no pueda enrostrársele su actitud que pretende clavar como por inadvertencia. (156)

Esos cuadros de pensamiento latinoamericano en la crisis se enriquecen si ampliamos la mirada y reparamos que, en 1952, el mismo año en que Getúlio Vargas funda el Banco de Desenvolvimento Econômico e Social (BNDES), uno antes de crear la Petrobras y dos previos a su propio suicidio, el crítico brasileño Antonio Candido dedica un ensayo a El Conde de Monte Cristo. Retrabaja el texto para una segunda edición en libro, en Tese e antítese (1963), poco antes de implantarse la dictadura. Explica en una nota de pie de página que su reflexión acompaña la de Gramsci, en Literatura y vida nacional, que en el personaje veía una encarnación del súper-hombre nietzscheano, como, a su modo, el compadre y el guarango.

Así como la venganza grupal disuelve al vengador en las redes del interés colectivo (...), la venganza personal lo destaca, marca su importancia en sí mismo y lo hace sobresalir por encima de los demás. El hombre que se venga a sí mismo cree poderosamente en sí mismo, y considera las violaciones de los otros a su propia integridad como otros tantos atentados al equilibrio del universo. Una visión parecida a la del gran industrial, quien justifica el desencadenamiento de una guerra si fuera útil al movimiento de sus negocios.

Por eso, en vez de darles a los hijos algo como De los Apeninos a los Andes — para mostrarles, en caldo azucarado, la tenacidad con que deben inculcarse los grandes sentimientos- la burguesía debió haberlos nutrido con dosis masiva de El Conde de Monte Cristo. No lecturas furtivas o marginales, pronto transformadas en pretextos para juego; sino también, y sobre todo, lecturas dirigidas, comentadas por el profesor, como parte magna del programa de las escuelas, con el fin de fundirlas en pensamiento y acción en todo momento. Pero sin picardía, desde luego, pues El Conde de Monte Cristo es un retrato completo de la 
venganza personal; y la venganza personal es la quintaesencia del individualismo; y el individualismo fue, y en cierto modo quiere seguir siendo, el eje de la conducta burguesa.

Tomado como compendio de moral, él habría enseñado a los niños y jóvenes, quienes lo leyeran por interés, a llevar hasta las últimas consecuencias los principios de la competencia y la apoteosis del éxito individual, nuevas formas del derecho del más fuerte y fundamentos éticos de la era capitalista. Edmundo Dantès (arribista como Rastignac y bonapartista como Julien Sorel) es uno de los muchos jóvenes que la literatura romántica tomó, en el siglo XIX, para ilustrar la nueva fase de conquista de la posición social mediante selección del talento y de la habilidad. En el fondo, la misma glorificación de la iniciativa y mano firme que vemos en Stendhal y Balzac. (Candido:111-112)

La venganza era una de las alegorías de Walter Benjamin, junto al Arte, el Amor, el Placer, el Arrepentimiento, el Tedio, la Destrucción, el Ahora, el Tiempo, la Muerte, el Miedo, el Dolor, el Mal, la Verdad, la Esperanza, el Odio, el Respeto, los Celos y los Pensamientos. Victor Hugo, JeanBaptiste Carpeaux o Théodore Géricault prodigaron figuras supliciadas o guillotinadas, vestigios de la venganza. Pero no nos alejemos del crítico brasileño. Analizando minuciosamente la novela de Dumas, Candido concluye entonces que:

La venganza, contemporánea constreñida o prudente del crédito moderno y de la industrialización, viejo ancestro, aparece aquí integrada en una nueva visión de la existencia. Gracias a ella, Monte Cristo pone en juego la capacidad humana (multiplicada en su tiempo) de actuar más libre y poderosamente sobre la naturaleza y sobre sus semejantes, liberándose de la coacción de una, y aprovechando al máximo el rendimiento del otro. Su vida de vengador científico realiza un sueño moderno: el advenimiento de un nuevo ritmo de vida, mediante el cual el espacio fuese reducido y el tiempo ampliado, mediante la movilidad mecanizada por una parte y la economía del gesto por la otra. Dueño de consciencias, conocedor de secretos, calculador infalible de los sentimientos y de los actos, puede estar en todas partes gracias a sus agentes automatizados como máquinas, a sus veloces embarcaciones a vela y a vapor, a los cambios de caballo que siembra por los caminos. (117)

Este es en parte el drama del Conde de Monte Cristo, hijo de su siglo, patriarca de los self-made-men, quien ignora la solidaridad y la igualdad, y que conoce tan sólo la subordinación y la dependencia requeridas también por su terrible sadismo. Héroe romántico por la apariencia fría y misteriosa que oculta pasiones indomables; por la infinitud de los deseos; por la excentricidad, el amor a los "paraísos artificiales» y al orientalismo, él todavía tiende al gusto por la sangre y por lo macabro, y por el refinamiento de la tortura moral que hacen de su venganza una obra de arte además de una obra científica. Su palidez, sus manos frías, les dan a algunos la idea de alguien de ultratumba, de un vampiro que se deleita con la sangre ajena. Ese vampirismo, por lo menos simbólico, está sin duda presente en su modo de ser, dándole un sentido peculiar a la frase «sediento de venganza» con la cual lo asociamos. (120)

Pero esa teoría de la venganza como encarnación de lo divino y contracara del iluminismo que, siendo meridional, como señalara Gramsci, es igualmente latinoamericana por donde se la mire, no estaría completa si no recordásemos que el concepto de venganza es una acción del verbo latino vindicare que significa simultáneamente tanto proteger como castigar. Borges, en efecto, la suele usar con el primer sentido de enaltecimiento pacífico y entonces, en el Evaristo Carriego 
(1930), conjetura que el tiempo, vindicación y corona europea de hombres numerosos de días, es sin embargo valor de más imprudente circulación en estas repúblicas. En Discusión (1932) nos informa que «Una vindicación del falso Basílides» $\mathrm{y}$ «Una vindicación de la cábala» son resignados ejercicios de anacronismo. Y en «La Biblioteca de Babel» nos dice en fin que las vindicaciones no son sino libros de apología y de profecía, que para siempre ensalzan los actos de cada hombre y guardan arcanos prodigiosos para su porvenir.

Su ejecutante, el vindex, se asocia, en eco, al iudex, es decir, remite al verbo latino dico: es quien dice al juez la violencia que le fue practicada a su cliente: vim dicere. En ese torneo, el proceso es una lucha simulada por la posesión de la cosa, mera reminiscencia de los actos de fuerza por los cuales se conquistaba y defendía la propiedad. Pero el vindex, agregan Ernout y Meillet, se vuelve así un defensor de la gran família a tal punto que los mismos diccionaristas recuerdan que fine, en irlandés, significa eso mismo, gran familia, lo cual nos llevaría a sospechar que Terry Eagleton tiene razón cuando argumenta que el Finnegans Wake configura un acto de venganza colonial en que el subordinado irlandés, desposeído de su lenguaje, desactiva la lengua inglesa dominante y la convierte en un festival de creación y chisporroteo, de la que sus propios dueños son incapaces. Una feliz guarangada.

Sabemos, en efecto, que la Work in Progress (aún no llamada Finnegans Wake) fue publicada, como un folletín, en casi todos los números (salvo el 9, 11, 14, 16-17, 19-20, 24 y 25) de una revista experimental de creación órfica, transition. En el último de esos números, el 25, donde excepcionalmente, no leemos ningún fragmento de Joyce, es posible, sin embargo, recoger una tesis de un escritor y antropólogo peruano, Luis Eduardo Valcárcel, de larga experiencia con teatro ritual en quíchua (D'ors 1925:204-206 y 2006:23), que nos propone a su modo una problematización identitaria latinoamericana. «There are several Americas», proclama Valcárcel en transition, que así recoge una suerte de manifiesto, publicado previamente por la revista de Mariátegui, donde argumenta que, como fruto del disenso que divide a las repúblicas, «se alzará el Yanqui. Frente a él las gentes de todos los pueblos pugnarán por entenderse en el idioma del común peligro». A esto sigue una clasificación más ardua, quizás, que la misma enciclopedia china de Borges:

1) Angloamericanos; 2) Latinoamericanos. Una de las campañas de unificación con indudable importancia es la de la extensión de la lengua castellana y el esfuerzo por conservarla. Tal sucede sobre todo en Antillas. Una segunda nomenclatura aparece: 1) angloparlantes y 2) hispanoparlantes. Habría que agregar 3) lusoparlantes. La primacía de las razas autóctonas hace indispensable la clasificación de 1) Indoamericanos o amerindios y 2) anglo, hispano, lusoamericanos.

El arte impone — sobre todo en arquitectura— la agrupación de las obras correspondientes al período de Usurpación Europea, en esta forma:

1) Ibero-aztecas o iberomejicanas, 2) ibero-inkas o iberoandinas. Los mestizajes fuerzan también a dividir América: 1) angloamericanos, 2) iberoamericanos, 3) afroamericanos, 4) asioamericanos.

Los del Perú como los de Méjico hablaremos de Indoamérica o de Amerindia; los de la Argentina de Latinoamérica; los de Canadá de Angloamérica.

Los yanquis son los únicos que se llaman «americanos» por antonomasia como sintetizando su programa de dominio continental. (Valcárcel:38-40)

Es conocida también la teoría de la soberanía de Carl Schmitt, para quien esta se presenta como la posibilidad de decidir acerca de la excepción, de tal suerte que no es la voluntad de un 
ser jerárquicamente superior la que define una decisión, sino la inscripción, en el cuerpo de la ley, de la exterioridad que lo anima y que lo mueve. Pensemos en la exterioridad de la ley tal como la representa Honoré Daumier en sus litografias «Gente de justicia» (1845-1848). Además, Agamben explica, en Homo sacer, que la decisión no concierne ni a una quaestio iuris ni a una quaestio facti, sino a la misma relación entre hecho y derecho.

Pero que la ley sea en su origen una lex talionis (talio provendría de talis, o sea que la ley del talión significa la ley de lo mismo) implica reconocer que el orden jurídico no sanciona un hecho transgresivo, sino que se constituye, en su misma repetición y sin cualquier sanción, en un estado de excepción. La violencia entra, pues, en el orden jurídico y hace, para Agamben, de la excepción la forma originaria del derecho, con lo cual lo que se moviliza no es otra cosa sino la culpa, idea manifiesta no sólo en la premisa de que la ignorancia de la norma no la elimina, sino también en el propio capitalismo, cuyo objetivo mayor, según supo ver Benjamin en su ensayo de 1921, es consagrarla, es decir, producir culpa («la venganza, contemporánea constreñida o prudente del crédito moderno», decía Antonio Candido). Reaparecen así los dos términos extremos del vindex, el protector y el verdugo.

Pero además, el mismo Agamben, en Signatura rerum, atribuye a Pierre Noailles el mérito de haber clarificado el significado de vindex. Recuerdo el pasaje:

Proviene, según la etimología tradicional, de vím dicere, literalmente: «decir o mostrar la fuerza». Pero ¿de qué «fuerza» se trata? Noailles observa que, en este sentido, entre los estudiosos reina la mayor confusión.

Ellos oscilan sin cesar entre dos sentidos posibles de la palabra: fuerza o violencia, es decir, la fuerza puesta materialmente en acto. En realidad, ellos no eligen, sino que proponen de vez en vez uno u otro significado. Las víndícationes del sacramentum son presentadas ya sea como manifestaciones de fuerza, ya sea como actos de violencia simbólicos o simulados. La confusión es aún mayor en lo que respecta al vindex. No resulta claro, de hecho, si la fuerza o la violencia que éste expresa es la suya propia, que pone al servicio del derecho, o la violencia del adversario, que denuncia como contraria a la justicia (...).

Contra esta confusión, Noailles muestra que la vis en cuestión no puede ser una fuerza o una violencia material, sino sólo la fuerza del rito, es decir, una «fuerza que obliga, pero que no tiene necesidad de aplicarse materialmente en un acto de violencia, aunque sea simulada» (...). Noailles cita a este propósito un pasaje de Aulio Gelio, en el cual la vis civilis quae verbo díceretur, «la fuerza civil (...) que se dice con la palabra», es opuesta a la vis quae manu fieret, cum vi bellíca et cruenta (la fuerza que se ejerce con las manos, con fuerza bélica y cruenta). Al desarrollar la tesis de Noailles, puede formularse la hipótesis de que la «fuerza dicha con la palabra» propia de la acción del vindex es la fuerza de la fórmula eficaz, como fuerza originaria del derecho. La esfera del derecho es, entonces, la de una palabra eficaz, de un «decir» que es siempre índicere (proclamar, declarar solemnemente), ius dicere (decir lo que es conforme al derecho) y vim dicere (decir la palabra eficaz). Si esto es verdad, entonces el derecho es por excelencia la esfera de las signaturas, en la cual la eficacia de la palabra prima sobre su significado (o lo realiza). Y, a la vez, todo el lenguaje muestra aquí su pertenencia originaria a la esfera de las signaturas. Antes que (o, mejor aún, además de) ser el lugar de la significación, el lenguaje es el lugar de las signaturas, sin las cuales el signo no podría funcionar. (Agamben:100-101) 
Dicho lo cual, podemos concluir que la venganza como fuerza ambivalente de protección y castigo es analógica. Lo admite Goya en sus grabados de Los desastres de la guerra: «Tan bárbara la seguridad como el delito» (1815) o "La seguridad de un reo no exige tormento» (1859). La venganza se mueve de singularidad a singularidad, anulando así la dicotomía entre lo general y lo particular, tan característica del pensamiento dialéctico, para proponernos un modelo bipolar donde no hay, en rigor, un origen o una arché sino que todo fenómeno actual es originario y toda imagen presente es arcaica. Si la ley no busca ya la palabra eficaz, sino la eficiencia misma que produce culpa, esta se ha desmaterializado y transformado apenas en un conjunto de signaturas que aguardan lectura e interpretación (la venganza no sólo es una obra de arte sino también una obra científica, una máquina antropológica).

Se vuelve más claro a nuestros ojos, de este modo, uno de los paradigmas más ostensibles del siglo XXI: la venganza. Lector de Nietzsche, Maurice Blanchot dice que la embriaguez tiene el inconveniente de darnos un sentimiento de poder. La actual sobrevivencia de la venganza no debe pues mostrarnos vectores temporales lineales, aunque regresivos, que pueden incluso presentar idas y vueltas contradictorias (Borges, que es superado por Martínez Estrada, que es superado por Gramsci, que es superado por Antonio Candido...). Nuestra actual percepción de la venganza en las sociedades latinoamericanas nos explica en cambio, por la vía de tiempos coextensivos, los efectos (frecuentemente catastróficos) de los pliegues temporales: un (nuevo) paradigma que ordena las series históricas de acuerdo con la metafísica de una memoria absoluta e infinita.

\section{Referencias bibliográficas}

Agamben, G. (2009). Signatura rerum. Sobre el método. Barcelona: Anagrama. Traducción de F. Costa y M. Ruvituso.

Antelo, R. (2016). Archifilologías latinoamericanas. Lecturas tras el agotamiento. Villa María: EDUVIM.

(2017). Cajón de sastre literario. Donde literatura y metaliteratura se entreveran. En C. Walker, editor. Mil hojas. Formas contemporáneas de la literatura. Santiago de Chile: Hueders.

Borges, J. L. (1994). Invectiva contra el arrabalero. El tamaño de mi esperanza. Barcelona: Seix Barral, 121-126.

Candido, A. (1991). Monte Cristo o de la venganza. Crítica Radical. Caracas: Biblioteca Ayacucho. Traducción de M. Russotto.

D'ors, E. (1925). Glosas sobre el teatro. Cinco minutos de silencio. Valencia: Sempere.

(2006). Teatro, títeres y toros: exégesis lúdica con una prórroga deportiva. Sevilla: Renacimiento.

Ludueña Romandini, F. (2017). La ascensión de Atlas. Glosas sobre Aby Warburg. Buenos Aires: Miño y Dávila.

Martínez Estrada, E. (1993). Radiografía de la pampa. Edición crítica de L. Pollmann. Madrid: CSIC,

Colección Archivos UNESCO.

Valcárcel, L. (1929). Hay varias Américas. Amauta, IV(20), 38-40. 